\title{
DETERMINAÇÃO DA CLASSIFICAÇÃO ANUAL DO ÍNDICE DE BALNEABILIDADE DA BACIA DO RIO ITAPOCU
}

\section{Resumo}

A utilização dos recursos hídricos para fins de recreação vem ganhando atenção especial por parte da população e dos governantes, uma vez que diversas doenças estão relacionadas a alterações dos níveis qualitativos da água. $\mathrm{O}$ objetivo deste estudo foi avaliar os parâmetros de Escherichia coli na bacia do rio Itapocu em quatro pontos distintos para determinar a classificação anual do índice de balneabilidade.Os parâmetros de cor verdadeira e turbidez foram avaliados de maneira complementar. As coletas foram realizadas entre junho de 2013 e maio de 2014, e os ensaios efetuados no Laboratório de Águas do Serviço Autônomo Municipal de Água e Esgoto de Jaraguá do Sul. Os índices dos parâmetros físicos, cor verdadeira e turbidez se mostraram muito bons. Já o parâmetro microbiológico Escherichia coli apresentou resultado péssimo, sendo considerado apenas um ponto como regular.

\section{$* * *$}

1 Especialista, e-mail: rafa.jung@uol.com.br

2 Doutor, e-mail: luizildo@catolicasc. org.br

Palavras-chave: Balneabilidade. Bacia do Itapocu. Escherichia coli. 


\section{INTRODUÇÃO}

Os recursos hídricos são fatores limitantes para o desenvolvimento sustentável. Assim, para a manutenção da sustentação local e regional, os recursos hídricos devem ser preservados, tanto em quantidade como em qualidade. (SALATI et al. in REBOUÇAS et al., 1999). A água, assim como os demais recursos naturais, sempre foi vista como imprescindível aos aspectos da vida. No percurso histórico da humanidade, ela sempre foi e será utilizada para beber, cozinhar, como meio de transporte, na recreação, na produção de alimentos e inúmeras outras utilidades. Há, ainda, quem credite à água poderes divinos.

\section{O DESENVOLVIMENTO}

\section{ECONÔMICO E SOCIAL}

DE QUALQUER PAÍS ESTÁ

FUNDAMENTADO NA

DISPONIBILIDADE DE ÁGUA

DE BOA QUALIDADE E NA SUA

CAPACIDADE DE CONSERVAÇÃO

E PROTEÇÃO DOS MANANCIAIS (MOTA, 1995). grau de pureza. A degradação da qualidade das águas é creditada aos constantes despejos de efluentes urbanos, de áreas agricultáveis e de efluentes industriais não tratados ou tratados de maneira inadequada (WHO, 2006; CARMO et al., 2005). As águas ainda podem ser negativamente afetadas pelo uso do solo na região e pelo próprio ciclo hidrológico.

A utilização dos recursos hídricos para fins de recreação vem ganhando atenção especial por parte da população e dos governantes, já que diversas doenças estão relacionadas a alterações dos níveis qualitativos da água. Neste sentido, em 2003, as estimativas apontavam cinco milhões de óbitos ao ano, na maioria crianças, ligados às doenças transmitidas pela água (WHO, 2003).

Ainda conforme a Organização Mundial da Saúde, ouso recreativo das águas ocorre de duas maneiras distintas: por contato primário e por contato secundário. Nas atividades de contato primário, há um risco razoável de que água seja engolida, inalada, ou entre em contato com orelhas, passagens nasais, membranas e mucosas ou através cortes na pele, permitindo a passagem de patógenos para o corpo.(HARRINGTON et al., 1993). Portanto, nestas atividades, o risco de contaminação é acentuado.

A World Health Organization - WHO (Organização Mundial da Saúde) afirma que diversos estudos epidemiológicos mostraram resultados de saúde adversos, incluindo infecções gastrointestinal e respiratórias, que podem ser associados à inalação ou ingestão de água contaminada ou o contato com organismos aquáticos patogênicos que vivem em águas recreativas poluídas. Isto pode resultar em 
um fardo significativo de doenças e perdas econômicas. Neste sentido, o monitoramento da qualidade do recurso hídrico pode gerar informações quantitativas e qualitativas sobre as condições microbiológicas, físicas e químicas, úteis para prevenção de doenças e fiscalizações legais.

Em locais de águas poluídas, podem ser encontrados bactérias, fungos, algas, vírus e protozoários nas mais diversas concentrações. Estes microrganismos são responsáveis por doenças, como disenteria, febre tifóide, giardíase, salmonelose, dentre outras. (OPAS, 2010; ALVES, 2007). As fontes de entrada destes microorganismos no meio aquático são bastante conhecidas, sendo as citadas anteriormente mais comuns.

Dentre os indicadores microbiológicos utilizados para classificação das águas para fins recreativos, encontram-se as bactérias do grupo coliformes, que é composto por bactérias pertencentes à família Enterobactereacea. Neste grupo, estão incluídas as bactérias Escherichia coli (E.coli), que se encontram em grande quantidade nas fezes e no trato intestinal de animais de sangue quente. Uma pessoa pode excretar bilhões destes microrganismos em um único dia. Desse modo, a probabilidade de encontrá-los nas águas é alta, apontando que houve contaminação pordejetos (ALVES, 2007).

Apesar da crescente demanda pelo uso recreacional de ambientes aquáticos e dos riscos decorrentes do contato com águas contaminadas, nota-se, no Brasil, uma carência de estudos e programas de monitoramento que avaliem as condições de balneabilidade, especificamente, em balneários de águas doces (VON SPERLING, 2003).
Desse modo, um dos indicadores importantes a serem estudados é o Índice de Balneabilidade (IB), que, segundo definição da Companhia Ambientaldo Estado de São Paulo (CETESB) e da Agência Nacional de Águas (ANA), é a qualidade das águas destinadas à recreação de contato primário, ou seja, atividades de natação, esqui aquático, mergulho, entre outras.

A Resolução 274/00, do Conselho Nacional do Meio Ambiente (CONAMA), vigente desde janeiro de 2001, trata do padrão de balneabilidade em praias e balneários de água doce e estabelece o monitoramento da qualidade da água semanal através da análise da concentração de indicadores microbiológicos, ou seja, coliformes termotolerantes, Enterococus ou $E$. coli, durante 5 semanas consecutivas, além de ter sua condição avaliada nas categorias própria e imprópria, sendo que a primeira poderá ser subdividida em: excelente, muito boa e satisfatória.

Além da forma descrita pelo Conama 274/00, a Cetesb desenvolveu uma metodologia que monitora, em caráter preventivo, as praias de boa qualidade, as quais denomina de "sistematicamente boas", com apenas uma amostragem mensal. Com base nas campanhas mensais, é realizada a classificação anual do ponto em questão. $\mathrm{O}$ indicador microbiológico utilizado é o Coliforme Termotolerante, Enterococus ou a Escherichia coli. As praias interiores de São Paulo são monitoradas pela Cetesb desde 1994. Esta metodologia,desenvolvida pela Cetesb, foi aplicada no estudo da bacia do Itapocu.

A inexistência de informações relacionadas às questões de balneabilidade na bacia do rio Itapocu e a preocupação relativa à falta de uma infraestrutura adequada para orientar os banhistas motivaram a realização deste estudo. 
É importante salientar que o rio Itapocu e seus contribuintes são passíveis de atividades recreativas, já que são classificados como classe II, em conformidade com a Portaria Estadual 24/79. O Art. 4o , III, c, da Resolução Conama $357 / 05$, menciona que as práticas de atividades recreativas de contato primário figuram entre os usos admissíveis para os rios enquadrados nas classes II, desde que sejam observadas as condições de balneabilidade.

Portanto, o presente estudo tem como objetivo avaliar os parâmetros de Escherichia coli em quatro pontos da bacia do Itapocu para determinar a classificação anual do índice de balneabilidade, sendo eles: rio Ano Bom, no município de São Bento do Sul, e rio Itapocu, nas localidades de Itapocu-Hansa, município de Corupá, Nereu Ramos e Três Rios do Norte, ambos no município de Jaraguá do Sul. Os parâmetros de cor verdadeira e turbidez serviram apenas para demonstrar que os aspectos estéticos da água não significam condições favoráveis à balneabilidade. O Art. 15, da Resolução Conama 357/05 (BRASIL,2005), menciona que o valor máximo de cor verdadeira deve ser de $75 \mathrm{mg}$ $\mathrm{PtCo} / 1$ (miligramas de Platina Cobalto por litro) e turbidez 100 NTU (unidade nefelométrica de turbidez).

\section{DESENVOLVIMENTO}

\section{1 Área de estudo e localização dos pontos de coleta}

A área de interesse deste estudo está localizada na região da Baixada Norte Catarinense. A bacia hidrográfica do Itapocu ocupa uma área de $3.160 \mathrm{~km}^{2}$ e é composta integralmente pelos municípios de Araquari, Corupá, Guaramirim, Schroeder e Jaraguá do Sul. Parcialmente inseridos estão: Barra Velha, Massaranduba, São
João do Itaperiú, São Bento do Sul, Campo Alegre, Joinville e Blumenau.

O rio Itapocu se forma no município de Corupá, a partir da junção do rio Humboldt com o rio Novo, a $90 \mathrm{~km}$ da foz. A Bacia do Itapocu abrange uma população de aproximadamente 500 mil habitantes. A nascente mais distante é a do rio Vermelho, no município de São Bento do Sul, a $136 \mathrm{~km}$ da foz do Itapocu, no município de Barra Velha. Na Figura 01, estão representadas a imagem da bacia hidrográfica e a localização dos pontos de amostragem. 


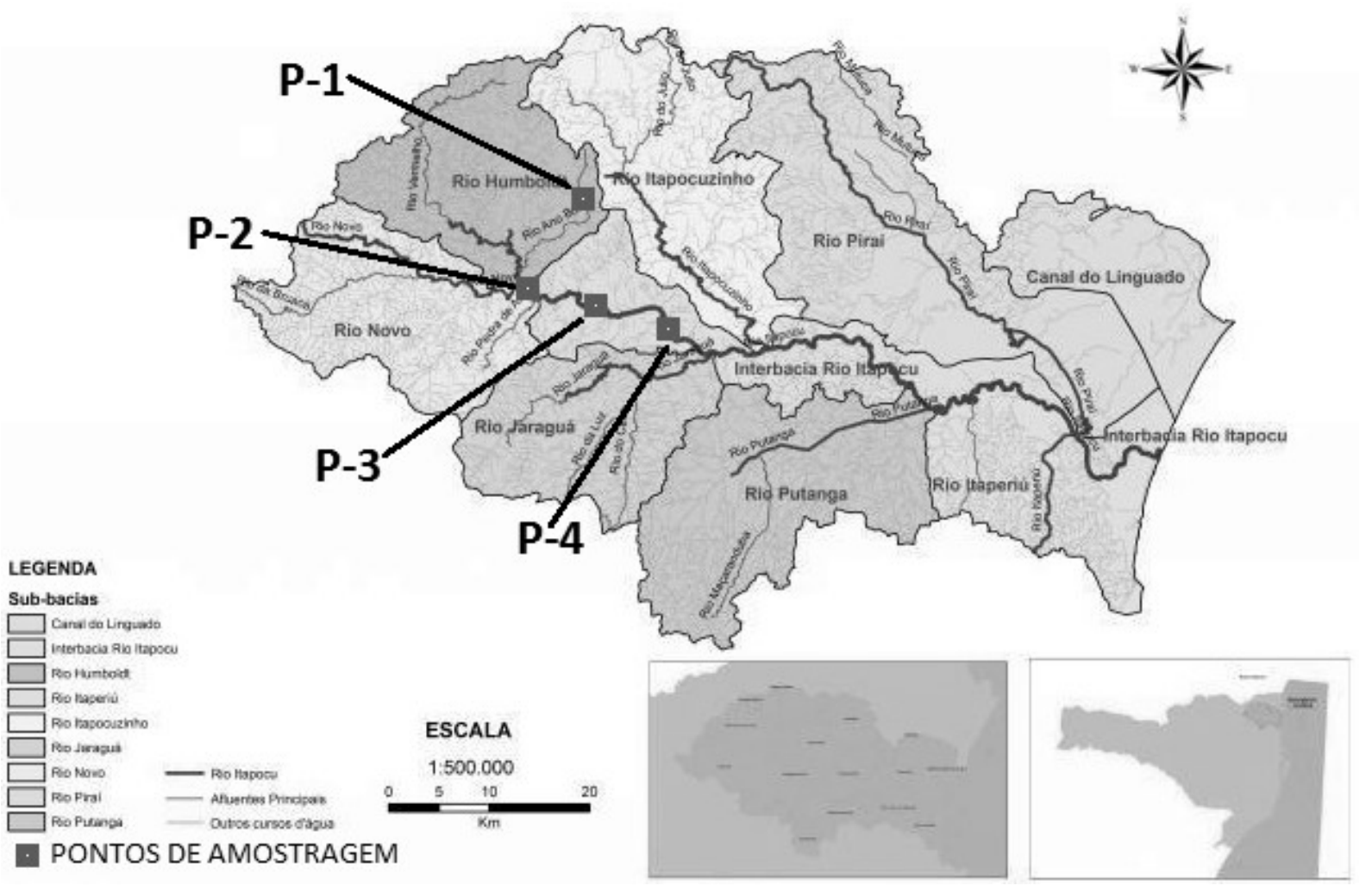

Fonte: Adaptado de Amvali (2014)

\section{FORAM DETERMINADOS}

QUATRO PONTOS AMOSTRAIS

PARA A REALIZAÇÃO DESTE

ESTUDO. CONFORME

DEMONSTRADO NA FIGURA 01,

O PONTO P-1 ESTÁ LOCALIZADO

NO RIO ANO BOM, UM DOS

FORMADORES DO RIO ITAPOCU,

SENDO OS DEMAIS P-2, P-3

E P-4 localizados No RIO

ITAPOCU, NOS MUNICÍPIOS DE

Corupá e Jaraguá do Sul.

As coletas foram realizadas, mensalmente, entre junho de 2013 e maio de 2014, sempre no período matutino. Os pontos foram divididos em dois grupos (P-1, $\mathrm{P}-2$ e $\mathrm{P}-3, \mathrm{P}-4)$, sendo as campanhas realizadas em dias diferentes para cada grupo. Ainda foram levantados os valores de precipitação nas 48 horas anteriores à coleta, pois, segundo Mota (2008), as águas pluviais, ao escoarem pelo solo, podem carrear impurezas dispersas na bacia de drenagem para os corpos hídricos superficiais, ocasionando a degradação da qualidade da água. Os dados pluviométricos foram obtidos na Estação Central de Tratamento de águas do Serviço Autônomo Municipal de Águas e Esgotos (Samae), de Jaraguá do Sul.

$\mathrm{Na}$ Tabela 01, é indicada a identificação dos pontos amostrais distribuídos na bacia do Itapocu, sua posição georreferenciada, a cidade de localização, o nome do rio e o código utilizado. 
Tabela 1: Identificação e posição geográfica dos pontos de coleta

\begin{tabular}{ccccc}
\hline Localização (rio) & Cidade & Código & Latitude & Longitude \\
\hline Rio Ano Bom & São Bento do Sul & P-1 & $26^{\circ} 23^{\prime} 07.54^{\prime \prime} \mathrm{S}$ & $49^{\circ} 12^{\prime} 37.72^{\prime \prime} \mathrm{O}$ \\
Rio Itapocu & Corupá & $\mathrm{P}-2$ & $26^{\circ} 25^{\prime} 52.81^{\prime \prime} \mathrm{S}$ & $49^{\circ} 14^{\prime} 09.12^{\prime \prime} \mathrm{O}$ \\
Rio Itapocu & Jaraguá do Sul & $\mathrm{P}-3$ & $26^{\circ} 26^{\prime} 47.73^{\prime \prime} \mathrm{S}$ & $49^{\circ} 09^{\prime} 53.06^{\prime \prime} \mathrm{O}$ \\
Rio Itapocu & Jaraguá do Sul & $\mathrm{P}-4$ & $26^{\circ} 26^{\prime} 54.10^{\prime \prime} \mathrm{S}$ & $49^{\circ} 07^{\prime} 47.33^{\prime \prime} \mathrm{O}$ \\
\hline
\end{tabular}

Fonte: Google Earth (2014)

$\mathrm{Na}$ Figura 02, demonstram-se as imagens dos pontos de coleta, datadas de 25 de junho de 2014.

Figura 2: Imagens dos pontos de coleta

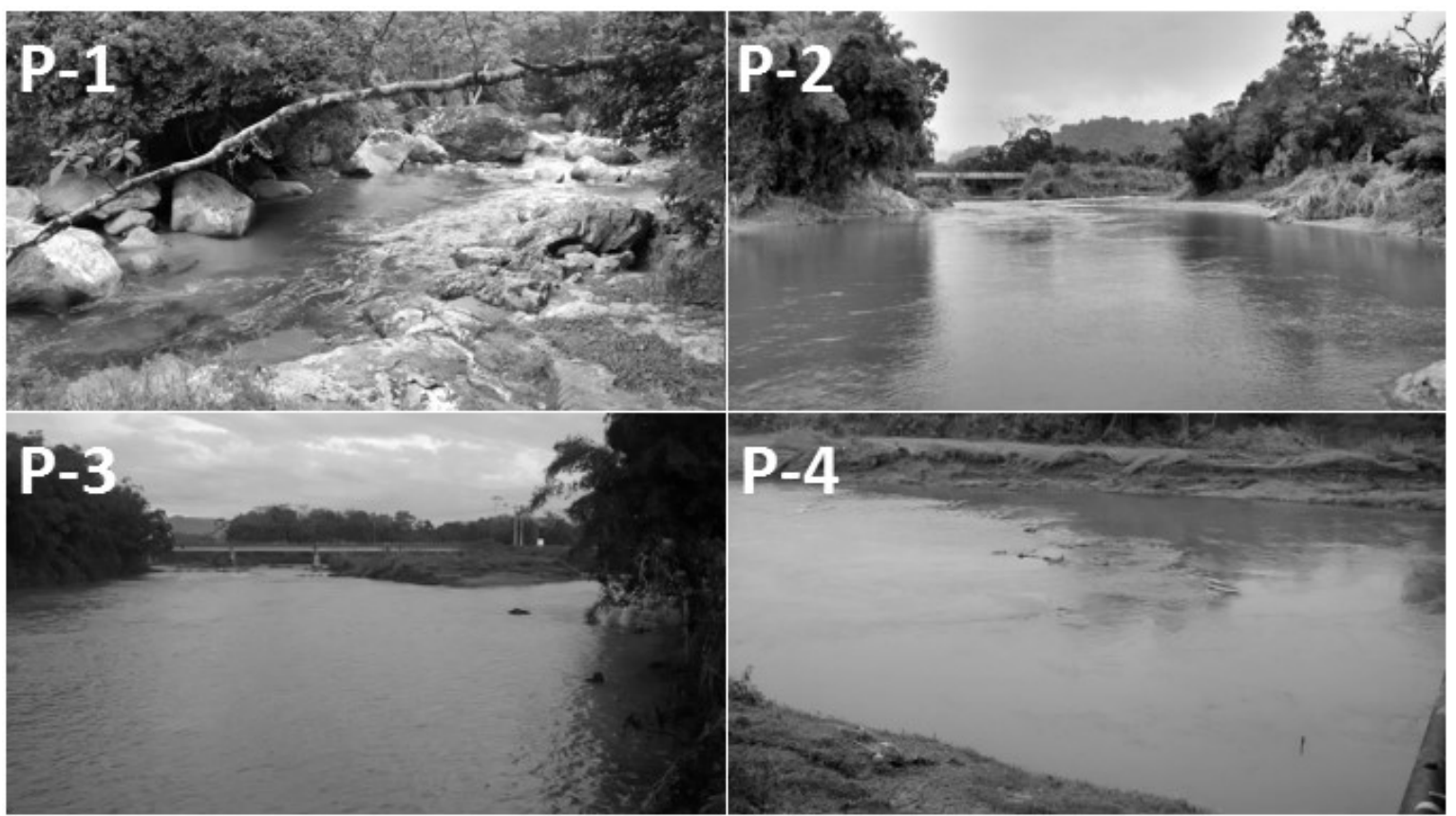

Fonte: Dos autores (2014)

Conforme o rio avança no sentido de sua foz, ocorrem mudanças significativas no seu leito e nas margens. As imagens da figura 02 mostram o quanto o rio sofre transformação. No ponto $\mathrm{P}-1$, por exemplo, encontram-se muitas pedras e corredeiras, o local é cercado por mata ciliar preservada. Este cenário é propício às águas de boa qualidade. Nos pontos $\mathrm{P}-2, \mathrm{P}-3$ e $\mathrm{P}-4$, o cenário é diferente. Nestes locais, o rio é mais caudaloso. No entanto, não há corredeiras e a mata ciliar praticamente inexiste. Esse cenário é propício para águas com nível de qualidade inferiorizado.

\subsection{Amostragem e Ensaios laboratoriais}

A amostragem foi realizada conforme a Norma Brasileira NBR 9898/87 - Preservação e 
Técnicas de Amostragem de Efluentes Líquidos e Corpos Receptores (ABNT,1987). Os ensaios foram realizados no Laboratório de Águas e Efluentes do Serviço Autônomo Municipal de Água e Esgoto (Samae) de Jaraguá do Sul, seguindo as normas do StandardMethods for the Examination of Water and Wastewater (APHA, 2011).

Como forma de avaliar o índice de balneabilidade dos pontos elencados na pesquisa, foi ensaiado o parâmetro inerente ao indicador microbiológico E. coli. Os aspectos físicos, cor verdadeira e turbidez objetivaram a demonstração que aspectos estéticos da água não significam condições favoráveis à balneabilidade.

O ensaio microbiológico foi realizado conforme o método 9221F (APHA, 2011) da norma anteriormente citada. O ensaio consiste da incubação de amostras em cartelas plásticas aluminizadas com 97 células, sendo 49 grandes e 48 pequenas. $\mathrm{O}$ método versa em utilizar $100 \mathrm{ml}$ de amostra ou diluição da amostra com água reagente. Esta amostra é transferida para um frasco de vidro estéril e junto a ela é adicionadoum sachê de substrato cromogênico. Neste estudo, foi utilizado o Colitag ${ }^{\circledR}$. Em seguida, o volume é transferido para a cartela plástica, estéril, e introduzida em uma seladora de cartelas. As cartelas já devidamente fechadas são incubadas em estufa microbiológica em temperatura de $35 \pm 2{ }^{\circ} \mathrm{C}$ por $24 \pm 2 \mathrm{~h}$.

Transcorrido o período de encubação, a cartela é colocada sob uma lâmpada ultravioleta (UV) com comprimento de onda de $365 \mathrm{~nm}$ e realizada a contagem das células que apresentam fluorescência. Com auxílio de uma tabela comparativa, os dados das células grandes e pequenas são cruzados e, deste modo, indicado o número mais provável (NMP) de E. coli por $100 \mathrm{ml}$.

O parâmetro de cor verdadeira foi ensaiado em espectrofotômetro de bancada Hach DR3800 com comprimento de onda de $455 \mathrm{~nm}$. O ensaio baseia-se em inserir uma cubeta com água reagente grau 1 no aparelho e realizar a zeragem do mesmo, descartar a água e transferir uma alíquota da amostra, previamente filtrada em filtro com porosidade de $0,45 \mu \mathrm{m}$, para a cubeta e realizar a leitura. O resultado é apresentado em $\mathrm{mg} \mathrm{PtCo/1,} \mathrm{diretamente,} \mathrm{no} \mathrm{visor} \mathrm{do} \mathrm{aparelho.}$

O parâmetro turbidez foi medido no turbidimetro de bancada Hach 2100Q. O ensaio de turbidez consiste na transferência de uma pequena alíquota da amostra para uma cubeta, que deve ser inserida no aparelho e realizada a leitura. $\mathrm{O}$ resultado é apresentado diretamente no visor do equipamento. A turbidez foi determinada pela escala NTU.Ambos os parâmetros físicos são realizados por colorimetria.

\section{3 Índice de Balneabilidade}

Para a determinação da classificação anual do índice de balneabilidade dos pontos amostrais da bacia do rio Itapocu, foi utilizado o método desenvolvido pela Cetesb, conforme citação anterior, em que os pontos são considerados como sistematicamente bons. Foi coletada uma amostra mensal em cada ponto.Para a obtenção do índice, foi utilizada o quadro comparativo para a classificação anual da qualidade do índice de balneabilidade. Os parâmetros foram desenvolvidos pela Cetesb e estão relacionados na sequência. 
Quadro 1: Especificações que determinam a qualidade das águas doces para fins de balneabilidade

\begin{tabular}{|c|c|}
\hline $\begin{array}{c}\text { Índice de } \\
\text { Balneabilidade }\end{array}$ & \multicolumn{1}{c|}{$\begin{array}{c}\text { Monitoramento mensal } \\
\text { Oútima } \\
\text { ou E. coli menores do que } 200 \text { em } 100 \% \text { do ano. }\end{array}$} \\
\hline Boa & $\begin{array}{l}\text { Número de resultados de Coliformes Termotolerantes menores do que } 1.000 \\
\text { ou E. coli menores do que } 800 \text { em } 100 \% \text { do ano, exceto a condição de menores } \\
\text { do que } 250 \text { e } 200 \text { em } 100 \% \text { do ano. }\end{array}$ \\
\hline Regular & $\begin{array}{l}\text { Número de resultados de Coliformes Termotolerantes maiores do que } 1.000 \\
\text { ou E. coli maiores do que } 800 \text { em porcentagem inferior a } 50 \% \text { do ano. }\end{array}$ \\
\hline Ruim & $\begin{array}{l}\text { Número de resultados de Coliformes Termotolerantes maiores do que } 1.000 \\
\text { ou E. coli maiores do que } 800 \text { em porcentagem entre } 20 \text { e } 50 \% \text { do ano. }\end{array}$ \\
\hline Péssima & $\begin{array}{l}\text { Número de resultados de coliformes Termotolerantes maiores do que } 1.000 \text { ou } \\
\text { E. coli maiores do que } 800 \text { em porcentagem igual ou superior a } 50 \% \text { do ano. }\end{array}$ \\
\hline
\end{tabular}

Fonte: Adaptado de Cetesb (2014)

\subsection{Resultados e Discussões}

As características encontradas para os parâmetros físicos de turbidez e cor verdadeira são apresentados na Figura 03, em que o parâmetro cor verdadeira oscilou entre o máximo de 79 mg $\mathrm{PtCo} / 1$, no mês de março, ao mínimo de $6 \mathrm{mg} \mathrm{PtCo} / 1$, em novembro, no ponto $\mathrm{P}-1$. No ponto $\mathrm{P}-2,51$ a $5 \mathrm{mg} \mathrm{PtCo} / 1$, nos meses de março e junho, respectivamente, 88 a $4 \mathrm{mg}$ $\mathrm{PtCo} / 1$ e 96 a 6 mg PtCo/l, nos pontos $\mathrm{P}-3$ e $\mathrm{P}-4$, respectivamente.

As coletas realizadas no P-1 e P-2 no mês de março sofreram influência da pluviometria que atingiu o índice de $110 \mathrm{~mm}$ nas 48 horas anteriores. Os pontos $\mathrm{P}-3$ e $\mathrm{P}-4$ atingiram os valores mais elevados de cor no mês de agosto, embora o volume de chuvas não tenha apresentado valores significativos nas 48 horas anteriores, sendo o volume acumulado de apenas $3 \mathrm{~mm}$.É importante salientar que a caracterização da coloração das águas depende de muitas variáveis, dentre elas a constituição do solo, das rochas, da vegetação etc. Neste caso, destaca-se particularmente a importância do solo, leia-se ferro e manganês, e da matéria orgânica, ambos dissolvidos ou em estado coloidal (LIBÂNIO et al., 2000). As chuvas limpam o solo e a vegetação, fazendo com que o material dissolvido e o coloide orgânico e inorgânico cheguem ao rio, ocasionando aumento de cor verdadeira. O material suspenso contribui para o aumento da turbidez.

Ao confrontar os resultados obtidos no parâmetro cor verdadeira com os elencados na Resolução Conama 357/05 para águas doces de classe II, pode-se concluir que os resultados alcançados se mostraram aceitáveis. Verifica-se, na figura 03 , que nos pontos $\mathrm{P}-3$ e $\mathrm{P}-4$ o valor ótimo ultrapassou o limite legal apenas uma única vez, no mês de agosto de 2013, sendo que nas demais campanhas os resultados mostraram-se dentro dos padrões de normalidade. Nos Pontos P-1 e P-2, o valor limite não foi ultrapassado em nenhuma das coletas. 
Figura 3: Relações entre Cor Verdadeira e Turbidez nos pontos amostrais

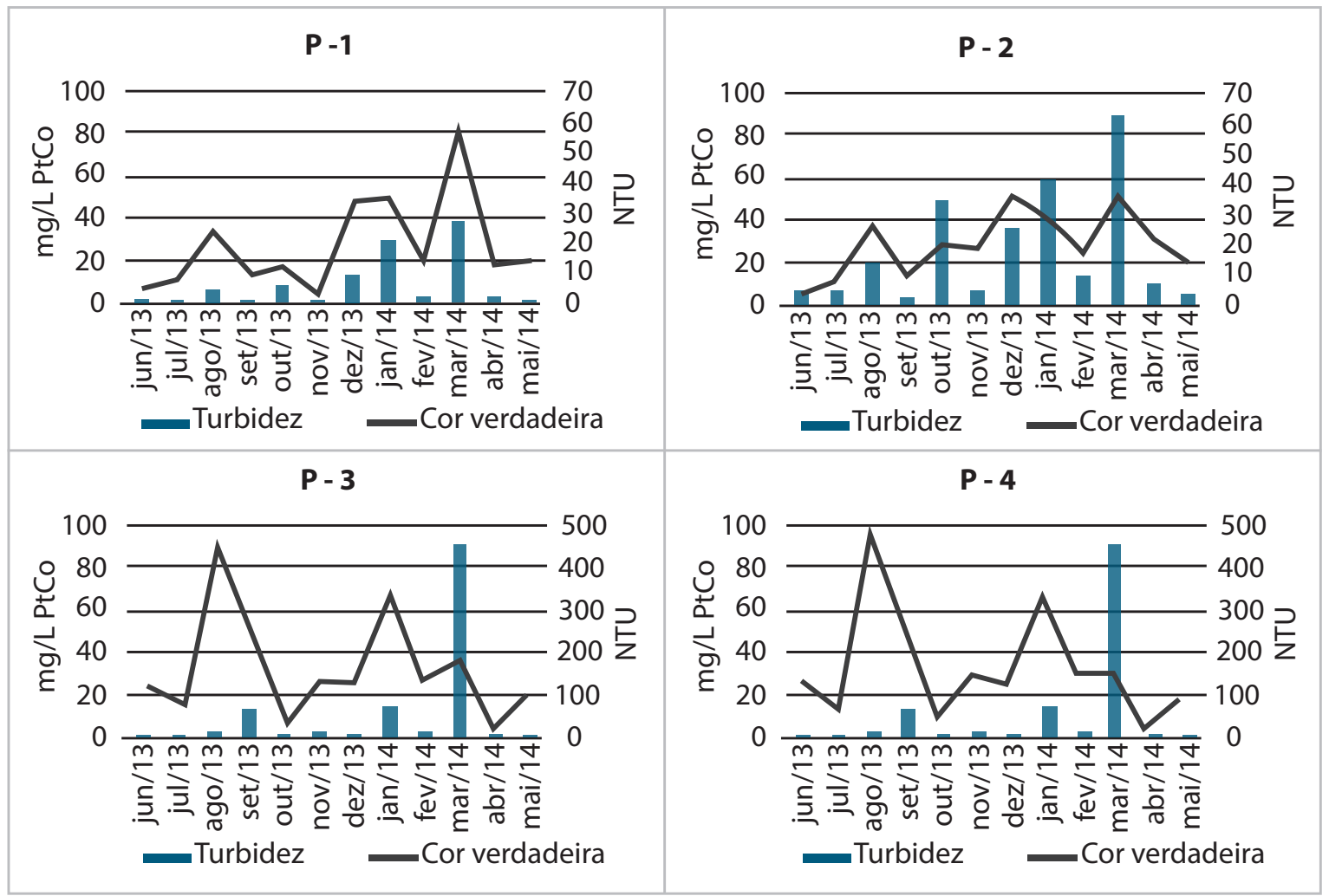

Fonte: Dos autores (2014)

O parâmetro turbidez flutuou entre os valores 1,02 a 27,6 NTU no ponto P-1. No P-2, os valores oscilaram entre 2,06 a 61,7 NTU.Já no ponto P-3, foram entre 3,0 e $452 \mathrm{NTU}$ e no ponto $\mathrm{P}-4$ foram encontrados os valores entre 3,46 e 418 NTU. Os valores mais elevados de turbidez em todos os pontos foram encontrados no mês de março de 2014. Isso se deve às condições climáticas desfavoráveis nas 48 horas anteriores à coleta, quando choveu $110 \mathrm{~mm}$.

A elevação da turbidez por influência das chuvas se deve ao fato do carreamento de materiais particulados, matéria orgânica e solo para o leito do rio. Nos meses em que os índices de turbidez apresentaram-se baixos, não houve ocorrência de precipitação nas 48 horas anteriores às campanhas de coleta.
Fazendo um paralelo com a Resolução Conama 357/05 para águas doces de classe II, pode-se verificar que, nos pontos $\mathrm{P}-1$ e $\mathrm{P}-2$, os resultados se apresentaram ótimos, não ultrapassando o limite de 100 NTU em nenhuma das 12 campanhas. Já nos pontos P-3 e P-4, os resultados foram bons, uma vez que o limite foi ultrapassado em apenas uma coleta, justamente no mês de março, por ocasião das chuvas fortes.

Quantoao parâmetromicrobiológico Escherichia coli, os pontos mostraram-se bastante distintos entre si. Os resultados obtidos e sua relação com os índices de pluviometria são observados na Figura 04. A linha pontilhada mostra o limite de $E$. coli, que é de 800 NMP. 


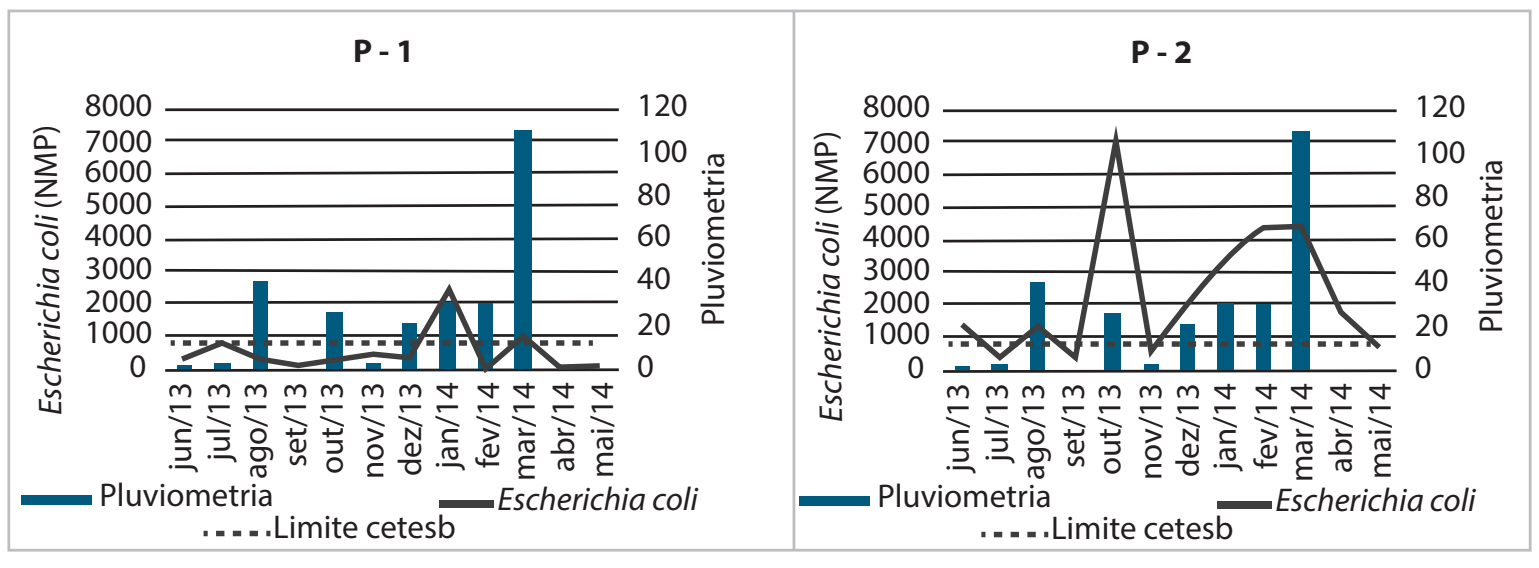

Fonte: Dos autores (2014)

Para o ponto $\mathrm{P}-1$, os valores apresentaram-se dentro dos padrões em $83,3 \%$ das campanhas. Apenas nos meses de janeiro e março de 2014 ultrapassaram os limites, 2406 e 932 NMP, respectivamente.Esse resultado causa preocupação, já que estes meses são bastante procurados por banhistas porocasião das elevadas temperaturas. Nestes meses, os índices pluviométricos das 48 horas anteriores à coleta apresentaram resultados de 30 e $110 \mathrm{~mm}$, respectivamente. Neste ponto, os resultados encontrados flutuaram entre os valores de 60,2 NMP até 2406 NMP por $100 \mathrm{ml}$ de amostra. O mês de fevereiro apresentou a melhor condição.

Quanto ao ponto amostral P-2, verifica-se que o mesmo não está em condições ideais de balneabilidade, já que os resultados obtidos estiveram em $67 \%$ do período acima do limite máximo permitido, em especial nos meses do verão, quando os resultados de E. coli se mantiveram acima do limite, justamente na época em que o balneário é mais procurado. Nos meses de julho, setembro, novembro e maio, os resultados estiveram dentro dos padrões. Nesses meses, ocorreram poucas chuvas, ou nenhuma, nas 48 horas anteriores. No Ponto $\mathrm{P}-2$, os resultados encontrados oscilaram entre 440 NMP a 6896 NMP por $100 \mathrm{ml}$, sendo que o mês de setembro apresentou a melhor condição e o mês de outubro a pior condição.

Os resultados microbiológicos obtidos nas 12 campanhas no ponto amostral P-3 estão representados graficamente na figura 05 .

Figura 5: Relação Escherichia coli x Pluviometria nos pontos P-3 e P-4

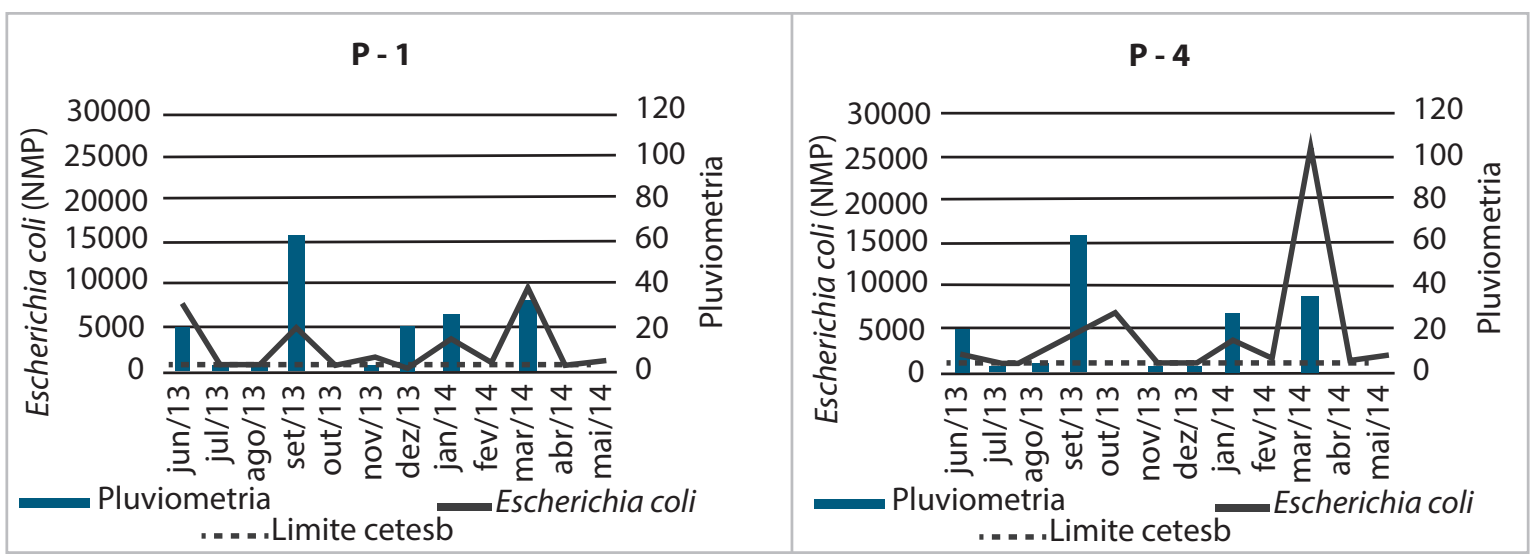

Fonte: Dos autores (2014) 
$\mathrm{Na}$ análise do ponto $\mathrm{P}-3$,é possível verificar que os índices pluviométricos se mostram decisivos nos resultados microbiológicos. É fácil perceber que, nos meses em que houve incidência de chuvas, os índices de $E$. coli apresentam-se acima do esperado para uma área propícia à prática de atividade aquáticas. Em 75\% das coletas, os resultados mostraram-se fora dos padrões, com destaque para quatro campanhas em que os resultados foram bastante acentuados, chegando a atingir o número de 9222 NMP. Neste ponto, os resultados flutuaram entre 418 NMP e 9222 NMP, nos meses de dezembro e março, respectivamente. Os meses de verão apresentaram resultados satisfatórios,já que dezembro e fevereiro atingiram resultados abaixo de 1000 NMP, em oposição, janeiro apresentou resultado de 4092 NMP. Porém, isso se deve ao índice de chuvas que atingiu o ponto nas 48 horas anteriores à coleta.

A Figura 05 ainda mostra os dados levantados no ponto amostral P-4. Verifica-se que os indices de contaminação microbiológicas já estão ultrapassando o máximo permitido em 92\% do periodo estudado. Apenas no mês de julho, o resultado não ultrapassou 800 NMP. Neste mês, o resultado foi de 690 NMP. No mês de março, foi encontrado o maior número de $E$. coli dentre todos os pontos de coleta e em todos os meses. Nesta ocasião, o resultado foi de 25993 NMP por $100 \mathrm{ml}$ de amostra.

Com base no quadro comparativo para a classificação anual da qualidade do índice de balneabilidade apresentado anteriormente, os dados foram calculados e os resultados estão apresentados na Tabela 02.

Tabela 2: Classificação anual de balneabilidade dos pontos pesquisados

\begin{tabular}{c|c}
\hline Ponto de coleta & Îndice de Balneabilidade \\
\hline $\mathrm{P}-1$ & Regular \\
$\mathrm{P}-2$ & Péssimo \\
$\mathrm{P}-3$ & Péssimo \\
$\mathrm{P}-4$ & Péssimo \\
\hline
\end{tabular}

Fonte: Dos autores (2014)

A análise da Tabela 02 demonstrou que o ponto amostral que apresentou o melhor resultado nos ensaios microbiológicos foi o P-1, localizado no rio Ano Bom. O ponto está localizado em área rural, envolto em vegetação de mata atlântica, na encosta da serra do mar. As campanhas realizadas durante o período de 12 meses revelaram que o ponto apresentou resultados menores que $200 \mathrm{NMP}$ de E. coli/100 ml em 33\% das ocasiões, o que é considerado ótimo pela Cetesb e pela Resolução Conama 274/2000. Em 50\% das ocasiões, os resultados apresentaram-se com menos de $800 \mathrm{NMP}$ de E. coli por $100 \mathrm{ml}$ de amostra, já descontados os quatro anteriores. Esse valor menor que 800 NMP é considerado bom por ambas as literaturas. Em 17\% das campanhas, o resultado foi maior que 800 NMP por $100 \mathrm{ml}$. No cruzamento dos dados analisados com o quadro comparativo da Cetesb, foi possível observar que a classificação anual do ponto $\mathrm{P}-1$ é regular. 
O ponto P-2 não obteve resultado de $E$. coli menor que 200 NMP em nenhuma campanha. Em 33\% das coletas, o resultado mostrou-se menor que $800 \mathrm{NMP} / 100 \mathrm{ml}$ e, em 67\% do período, o resultado foi maior que 800 NMP. Esses resultados apresentados credenciaram o ponto a receber a classificação anual como péssimo, conforme observado na tabela 02 .

Outro ponto que apresentou resultados preocupantes foi o P-3. Neste local, também não se obteve resultados menores que 200 NMP de E. coli em nenhuma das 12 coletas realizadas. Em 25\% das oportunidades, os resultados apresentaram-se como bons, com valores menores que 800 NMP. Todavia, em 75\% das coletas, os resultados foram péssimos, com valores superiores a $800 \mathrm{NMP} / 100 \mathrm{ml}$ de amostra, conforme apresentado na Figura 05. Até mesmo nas coletas em que não ocorreu a incidência de chuvas nas 48 horas anteriores, os valores mostraram-se elevados. Esses resultados demonstraram que a classificação anual é considerada péssima.

O ponto $\mathrm{P}-4$, na localidade de Três Rios do Norte, foi o que apresentou os piores resultados microbiológicos. Nas 12 campanhas, não foi possível obter resultados menores que 200 NMP de E. coli por $100 \mathrm{ml}$ de amostra. Em apenas uma oportunidade, $8 \%$, o resultado foi menor que 800 NMP. Em 92\% das coletas, o resultado foi maior que $800 \mathrm{NMP}$, considerado impróprio às práticas de atividades de contato primário. Igualmente, o no ponto $\mathrm{P}-3$, os dias de estiagem também não fizeram com que os resultados fossem atenuados. Por ocasião dos resultados obtidos durante o ano, a classificação anual deste ponto é considerada péssima.

$\mathrm{Na}$ Figura 06, demonstram-se gráficos com as relações entre os parâmetros de Escherichia colie turbidez. Os índices apresentados representam o valor real dividido pelo valor limite, sendo $1 \mathrm{o}$ índice limite em ambos parâmetros. Observa-se que, no ponto $\mathrm{P}-1$, os valores de E. coli ultrapassam o limite em cujos meses a turbidez tem uma pequena elevação ante os demais. O Ponto $\mathrm{P}-2$ já não apresenta relação latente entre a turbidez e a Escherichia coli.O parâmetro microbiológico permanece na maior parte do tempo acima do limite, mesmo a turbidez apresentando certa estabilidade durante o ano.

Ainda conforme a Figura 06, o ponto P-3 só apresentou relação entre Escherichia coli e turbidez no mês de março. Assim, é possível analisar os picos no mês citado. Março é o único mês em que a turbidez excedeu o limite imposto pela Resolução Conama 357/05. O mesmo cenário é apresentado no ponto P-4, sendo março o mês com os maiores resultados de E. coli e turbidez.

Os resultados encontrados nestas campanhas evidenciam que não há uma relação direta entre a turbidez e o parâmetro microbiológico. Mesmo em meses de turbidez baixa, os resultados de E. coli ultrapassam os limites toleráveis para práticas de contato primário com o ambiente aquático. Entretanto, diversos estudos evidenciam que o aumento de turbidez nas águas naturais pode levar ao aumento dos contaminantes microbiológicos. Conforme Martins (2012), independentemente da execução de atividades na bacia, os próprios fenômenos naturais de erosão e carreamento de partículas para os cursos d'água podem implicar um aumento da turbidez e concentração de organismos, inclusive patogênicos, no curso d'água. 
Figura 6: Relação dos parâmetros Escherichia coli x Turbidez

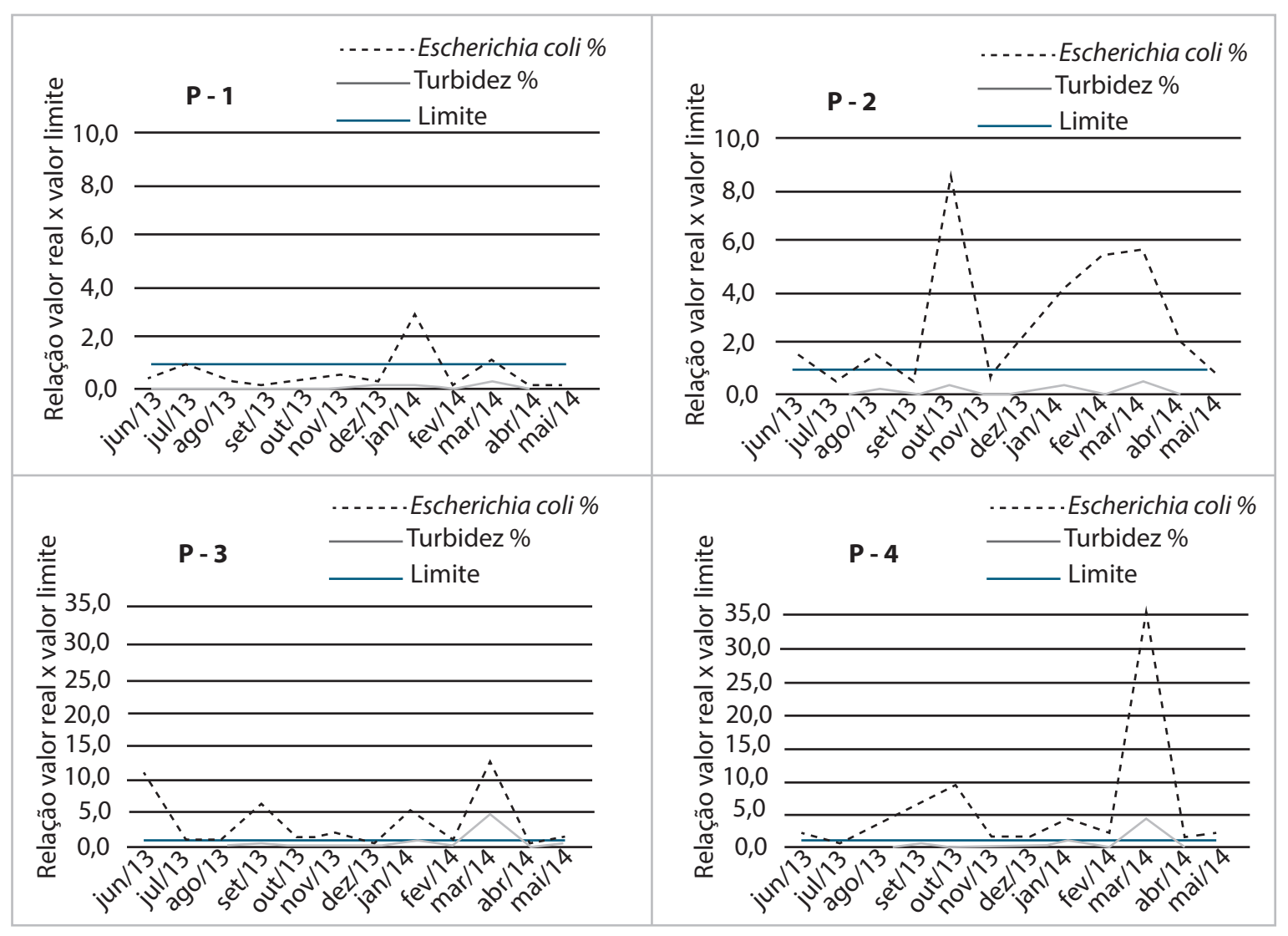

Fonte: Dos autores (2014)

O índice de turbidez está intrinsicamente ligado à pluviometria. Segundo Mota (2008), as águas pluviais, ao escoarem pelo solo, podem carrear impurezas dispersas na bacia de drenagem para os corpos hídricos superficiais, ocasionando a degradação da qualidade da água.
Cunha et al. (2004), ao analisarem a qualidade microbiológica de quatro rios do baixo curso do Amazonas, próximos às cidades de Macapá e Santana (AP), identificaram a existência da relação entre precipitação e aumento da concentração de Escherichia coli.

\section{CONSIDERAÇÕES FINAIS}

O rio Itapocu e o rio Ano Bom são considerados aptos para as práticas de atividade de contato primário, tais como atividades de natação, esqui aquático, mergulho, entre outras, conforme a Portaria Estadual 24/79 e a Resolução Conama 357/05. Entretanto, os ensaios laboratoriais não evidenciaram a mesma condição descrita na legislação.

Os ensaios microbiológicos revelaram que o ponto amostral P-1 está apto para atividades de contato primário, desde que não ocorram chuvas fortes no dia anterior. 
Índices pluviométricos acumulados em 48 horas, quando maiores que $30 \mathrm{~mm}$, ocasionam inaptidão do ponto $\mathrm{P}-1$ para atividades de contato primário, conforme se verificou no estudo.

\section{Nos Pontos P-2, P-3 e P-4,} NÃO SÃO RECOMENDADAS PRÁTICAS DE ATIVIDADES DE CONTATO PRIMÁRIO.

Os ensaios dos parâmetros físicos não evidenciaram impedimento quanto às práticas de atividades aquáticas, sendo que os pontos $\mathrm{P}-1$ e $\mathrm{P}-2$ são considerados como ótimos, e os pontos $\mathrm{P}-3$ eP-4 são considerados satisfatórios. Todavia, os ensaios microbiológicos apresentaram elevados níveis de $E$. coli, não atendendo aos padrões de qualidade determinados pela Resolução Conama 274/00 para fins de balneabilidade. Desta maneira, é confirmado o fato levantado anteriormente, de que os aspectos estéticos da água não significam condições favoráveis à balneabilidade.

Durante as 12 campanhas não se pôde comprovar diretamente uma relação entre a turbidez e Escherichia coli. No entanto, estudos mais aprofundados podem ser realizados, já que diversas pesquisas comprovam esta relação.

De forma geral, o rio Itapocu apresentou uma condição péssima de balneabilidade e devem, portanto, ser evitadas as práticas de atividades que exponham a pessoa a ter contato direto com suas águas. $\mathrm{O}$ rio Ano Bom apresentou uma condição satisfatória. Nos meses em que o resultado saiu da normalidade, houve alto índice de precipitação nas 48 horas anteriores à amostragem, podendo essa alteração dos resultados ser creditados às chuvas. De maneira simplória,o rio Ano Bom estaria em condição de receber os banhistas, sem expô-los às condições insalubres de balneabilidade.

Os resultados encontrados requerem atenção das autoridades de vigilância sanitária e de saneamento ambiental, para que estratégias que visem à saúde dos banhistas sejam desenvolvidas e, efetivamente, colocadas em prática.

Frente aos fatos e resultados apresentados, algumas ações para o acompanhamento da balneabilidade nos rios Itapocu e Ano Bom são sugeridas, ou seja: a elaboração de um plano para o monitoramento; fornecer um canal de informação com o usuário, através de placas de sinalização da qualidade da água; pesquisar informações sobre a relação entre doenças gastrointestinais e frequentadores das praias; maior abrangência das Estações de Tratamento de Efluentes (ETE) no município de Jaraguá do Sul; e construção de ETE nos municípios de Corupá e São Bento do Sul.

Porém, considerando a climatologia da região e sua influência nas características físico-químicas e microbiológicas da água, bem como a falta de estudos referentes ao tema na bacia do Itapocu, não é possível assegurar os índices de classificação anual dos pontos pesquisados. Isso porque, mesmo apresentando resultados desconformes em alguns pontos e conformes em outros, o resultado poderá sofrer alterações significativas com a ocorrência ou não de chuvas, já que enxurradas acabam por carrear matéria orgânica, o que influencia os parâmetros analisados, principalmente nas concentrações de $E$. Coli.Assim, sugere-se a elaboração de um novo estudo no período de um ano, porém com coleta de amostras semanais, para melhor caracterizar a balneabilidade desses locais. 


\section{DETERMINATION \\ OF THE ANNUAL \\ CLASSIFICATION OF \\ THE ITAPOCU RIVER \\ BASIN BALNEABILITY \\ INDEX}

\begin{abstract}
The use of the water resources for recreational purposes has gained special attention from the population and from the government, since several diseases are related to changes in the quality standards of water. The objective of this study was to evaluate the Escherichia coliparameters in the Itapocuriver basin, in 4 different points, to determine the annual classification of the balneability index. The real color and turbidity parameters were evaluated in a complementary manner. The samples were collectedfrom June 2013 to May 2014, and the analyses were performed at the Water Laboratory from the Municipal Autonomous Service of Water and Wastewater from Jaraguá do Sul. The physical parameters index, such as real color and turbidity, were excellent. On the other hand, the microbiologicalparameter Escherichia colipresented a poor result, and only one point was considered regular.
\end{abstract}

Keywords: Balneability. Itapocu

River basin. Escherichia coli.

\section{REFERÊNCIAS}

ALVES, Marina Gumiere. Bactérias na água de abastecimento da cidade de Piracicaba. 2007. Dissertação, 102 f. Dissertação (Mestrado em Agronomia) - Escola Superior de Agricultura Luiz de Queiroz - ESALQ.Piracicaba. 2007.

\section{AMERICAN PUBLIC HEALTH}

ASSOCIATION - APHA. Standard Methods for the Examination of Water and Wastewater. 22nd. ed. Washington, 2011.

AMVALI. Histórico e documentos. 2014.

Disponível em: <http://zip.net/bmtxYJ>. Acesso em: 02 maio 2014.

ASSOCIAÇÃO BRASILEIRA DE NORMAS TÉCNICAS - ABNT. NBR 9898: Preservação e Técnicas de Amostragem de Efluentes Líquidos e Corpos Receptores. Rio de Janeiro: ABNT, 1987.

BRASIL. Conselho Nacional do Meio Ambiente. Resolução Conama 274, de 29 de novembro de 2000. Define os critérios de balneabilidade em águas brasileiras. Disponível em: < http://zip.net/bctx42 >. Acesso em: 02 maio 2014.

Conselho Nacional do Meio Ambiente.

Resolução Conama 357, de 18 de março de 2005. Dispõe sobre a classificação dos corpos de água e diretrizes ambientais para o seu enquadramento, bem como estabelece as condições e padrões de lançamento de efluentes, e dá outras providências. Disponível em: <http://zip.net/bqty22>. Acesso em: 02 maio 2014.

CARMO, Marciléia Silva do; BOAVENTURA, Geraldo Resende; OLIVEIRA, Edivan Costa. Geoquímica das águas da bacia hidrográfica do rio Descoberto, Brasília/ DF - Brasil. Química Nova, v. 28, n. 4, p. 565-574, 2005.

CUNHA, Alan Cavalcanti et al. Qualidade microbiológica da água em rios de áreas urbanas e periurbanas no baixo Amazonas: o caso do Amapá.

Revista Brasileira de Engenharia Sanitária e Ambiental, v. 9, n. 4, p. 322-8.

DI BERNARDO, Luiz; PAZ, Lídia Patrícia Sabogal. Seleção de tecnologias de tratamento de água. São Carlos: LDIBE, 2008.

GOOGLE Earth. Programa de apresentação tridimensional do globo terrestre. Disponível em: <http://zip.net/bptyKY>. Acesso em: 20 abr. 2014.

HARRINGTON, Jon. F. et al. The health of Sydney surfers: an epidemiological study. Water Science and Technology. v. 27. n.3-4. p. 175-181. Austrália. 1993. 
LIBÂNIO, Marcelo. et al. Avaliação da Relevância do Carbono Orgânico Total como Parâmetro de Caracterização de Águas de Abastecimento. Revista Brasileira de Recursos Hídricos, v. 5, n. 4, p. 41-55. 2000.

MARTINS, Luana K. L. Alves. Contribuições para Monitoramento de Balneabilidade em Águas Doces no Brasil. 2012. 139 f. Dissertação (Mestrado em Saneamento, Meio Ambiente e Recursos Hídricos) - Universidade Federal de Minas Gerais, Belo Horizonte, 2012.

MOTA, Suetônio. Gestão ambiental de recursos hídricos. 3. ed. Rio de Janeiro: ABES, 2008.

Preservação e conservação de recursos hídricos. Rio de Janeiro: ABES, 1995.

ORGANIZAÇÃO PAN-AMERICA DA SAÚDE - OPAS. Guia de Trabalho sobre a Água: Água, cada gota conta vamos usá-la com sabedoria. 2014. Disponível em: <http://zip.net/bhtx8Y> Acesso em: 27 maio 2014.

SÃO PAULO. Companhia de Tecnologia de Saneamento Ambiental do Estado de São Paulo

- CETESB. Índice de balneabilidade. 2014.

Disponível em:<http://zip.net/bktx9v>. Acesso em: 02 maio 2014

SALATI, Enéas; SALATI, Eneida; LEMOS, Haroldo Mattos de. Água e o desenvolvimento sustentável. In: Águas doces no Brasil: capital ecológico, uso e conservação. São Paulo: Escrituras Editora, 1999.

SANTA CATARINA. Portaria Estadual no 24 de 19, de setembro de 1979. Enquadra os cursos d'água do Estado de Santa Catarina. Disponível em: <http:// zip.net/bgtx4h>. Acesso em: 30 abr. 2014

VON SPERLING, Eduardo. Água para saciar corpo espírito: Balneabilidade e outros usos nobres. In:

Anais XXII Congresso Brasileiro de Engenharia Sanitária e Ambiental. ABES, Joinvile, 2003.

WORLD HEALTH ORGANIZATION WHO. Guidelines for safe recreational water environments: coastal and fresh waters. Vol.1, WHO, 2003.

\section{Guidelines for drinking-water}

quality: incorporating first addendum. Vol. 1, Recommendations. 3rd ed. WHO, 2006.

Data de recebimento: 17/09/2014

Data de aprovação: 13/12/2016

\section{SOBRE OS AUTORES}

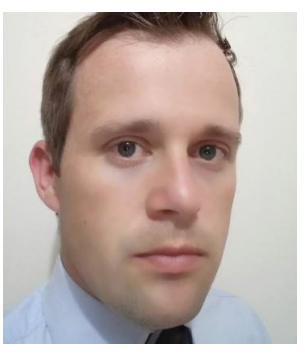

\section{Rafael Jungton}

Tecnólogo Ambiental graduado pelo Centro Universitário Católica de Santa Catarina - Campus Jaraguá do Sul (2012), Pós-Graduado em Gerenciamento de Águas e Efluentes pelo Serviço Nacional de Aprendizagem Industrial - SENAI/ SC (2014). Foi Coordenador de campo do Projeto Comunitário realizado pelo Centro Universitário Católica de Santa Catarina no bairro João Pessoa com objetivo de conscientização da comunidade com as questões inerentes ao meio ambiente.Laureado com o certificado de Honra ao Mérito Pe. Elemar Scheid, por ter obtido o melhor desempenho acadêmico no Curso superior de Tecnologia em Gestão Ambiental do CentroUniversitário Católica de Santa Catarina. Atualmente é servidor público municipal e atua a 7 anos nos laboratórios de águas e efluentes do Serviço Autônomo Municipal de Água e Esgoto - Samae, de Jaraguá do Sul. Faz parte da equipe responsável pela implantação da Norma ABNT NBR ISO/IEC 17025-2005, atuando como substituto do Gerente da Qualidade.Integrante titular do Conselho Municipal de Segurança Alimentar e Nutricional - Consea de Jaraguá do Sul.

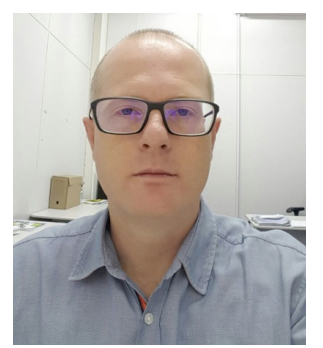

\section{Luizildo Pitol Filho,} Dr.

Possui graduação em Engenharia Química pela Universidade Federal de Santa Catarina (1996), mestrado em Engenharia Química pela Universidade Federal de Santa Catarina (1999) e doutorado em Chemical and Process Engineering - Universitat Rovira i Virgili (2007). Tem experiência nas áreas de Engenharia Química-principalmente em processos de separação envolvendo membranas, adsorção e 
fluidos supercríticos, e em petróleo e craqueamento catalítico; Engenharia dos Materiais - principalmente na produção de membranas e microcápsulas poliméricas, utilizando ou não micromixers; Engenharia Ambiental - sobretudo na gestão de recursos hídricos; Fenômenos de Transporte - principalmente mecânica dos fluidos e transferência de calor.Como recém-doutor, foi pesquisador contratado pelo Departamento de Engenharia Mecânica da Universidade de Maribor,Eslovênia, de abrilde 2008 a abril de 2009. Atualmente é professor colaborador da Universidade do Vale do Itajaí (UNIVALI).

\section{***}


